\title{
Aprendendo a ser mulher no cárcere
}

Isabela Cristina Alves Araújo ${ }^{1}$

Luana Hordones Chaves ${ }^{2}$

\section{Resumo}

As prisões femininas nascem no Brasil com o objetivo de readequar as mulheres dentro das expectativas dos tradicionais papéis sociais de gênero a elas designados. E isso significa que, devido às diferenças biológicas, há posições distintas para homens e mulheres ocuparem na sociedade. Às mulheres, segundo os padrões construídos tradicionalmente, caberiam as funções domésticas e o trabalho relacionado ao cuidado. Se essa realidade era visível no início da história das instituições prisionais direcionadas exclusivamente às mulheres, na década de 30 , observamos que as unidades atuais não se distanciam substantivamente desses objetivos. Muros rosas, necessidade do aprendizado do trabalho doméstico, idealização da maternidade e promoção dos "dias de beleza", dentre outros discursos como do "amor bandido", são ainda recorrentes e valorizados no cárcere feminino. Com o propósito de abordar as expectativas dos papéis de gênero no sistema de justiça criminal, neste trabalho analisamos os resultados qualitativos e quantitativos de uma pesquisa realizada durante os anos de 2017 e 2018 nas duas unidades prisionais exclusivamente femininas da Região Metropolitana de Belo Horizonte: o Centro de Referência à Gestante Privada de Liberdade e o Complexo Penitenciário Estevão Pinto. A presente análise se centra nos resultados do survey aplicado às detentas das duas instituições, assim como nas entrevistas com mulheres presas e parte da equipe técnica de cada unidade. Para tanto, abordamos temas relacionados à maternidade, à sexualidade, às relações conjugais, ao cotidiano prisional e, em última instância, ao aprendizado do "ser mulher". Tratamos, nesse contexto, tanto das trajetórias de mulheres presas e de suas vivências na prisão, como das narrativas que compõem a punição a que estão submetidas no cárcere. Os resultados mostram que os tradicionais papéis de gênero ainda regem, em grande medida, as prisões femininas de Minas Gerais, dado o esforço para enquadrar as mulheres privadas de liberdade nessas expectativas sociais.

\section{Palavras-chave}

Prisão. Encarceramento feminino. Papéis de gênero.

1 Doutoranda em Sociologia pela Universidade Federal de São Carlos (UFSCar). E-mail: isabelacristina1903@gmail.com.

2 Doutora em Sociologia e Residente pós-doutoral no Departamento de Sociologia da Universidade Federal de Minas Gerais (UFMG). E-mail: luanahordones@hotmail.com. 


\begin{abstract}
Women's prisons emerge in Brazil aiming to adapt women within the expectations of the traditional social and gender roles designated to them. This means that, because of biological differences, there are distinct positions for men and women to occupy in society. Women, according to traditionally constructed standards, are suitable for domestic functions and carerelated work. If this reality was visible at the beginning of the history of prisons exclusive to women, in the 1930s, we observed that current units do not substantially distance themselves from these objectives. Pink walls, the need to learn housework, the idealization of motherhood, the promotion of "beauty days", and other speeches such as "dangerous love", are still recurrent and valued in the female prison. With the purpose of addressing the expectations of gender roles in the criminal justice system, in this paper we analyze the qualitative and quantitative results of a research conducted between 2017 and 2018 in the two exclusively female prisons of the Metropolitan Region of Belo Horizonte: The Reference Center to Pregnant Women Deprived of Freedom and the Estevão Pinto Penitentiary Complex. The present analysis focuses on the results of the survey applied to the inmates of the two institutions, as well as the interviews with women prisoners and part of the technical team of each unit. For this, we tackle themes related to motherhood, sexuality, conjugal relationships, prison life and, in the last instance, learning how to "be a woman". In this context, we deal with both the trajectories of imprisoned women and their experiences in prison, as well as the narratives that make up the punishment they are subjected to in prison. The results show that traditional gender roles still largely govern women's prisons in Minas Gerais, given the effort to frame women deprived of freedom in these social expectations.
\end{abstract}

\title{
Keywords
}

Prison. Female incarceration. Gender roles.

\section{Introdução}

Em agosto de 2017, iniciamos o trabalho de campo da pesquisa cujos dados analisamos neste artigo, com visitas semanais ao Centro de Referência à Gestante Privada de Liberdade (CRGPL) para entrevistarmos internas e profissionais da unidade. Era a primeira fase da pesquisa e nosso primeiro contato com uma unidade materno-infantil. Uma de nossas entrevistadas, Paula $^{3}$, desde sua chegada para nosso encontro e durante toda a entrevista, manteve seus olhos um pouco abaixo dos nossos, ombros encolhidos, braços

${ }^{3} \mathrm{O}$ nome utilizado é fictício, a fim de garantir o anonimato da entrevistada. 
ocupados acalentando seu bebê. Ela andava devagar, devido à osteomielite que deixara sua perna com feridas abertas. Paula agradecia constantemente a oportunidade de estar no Centro e não em uma unidade prisional convencional. Ela nos contou como um relacionamento abusivo a deixou submissa às vontades do ex-companheiro, o que acabou resultando em sua prisão. Ali em nossa frente estava uma mulher visivelmente fragilizada.

Nosso reencontro com Paula se deu cerca de seis meses depois. Ela não estava mais no Centro de Referência à Gestante Privada de Liberdade (CRGPL), e sim na Penitenciária Industrial Estevão Pinto (PIEP), onde realizamos a segunda parte das entrevistas para a pesquisa. Paula andava de forma altiva, olhar elevado, ria alto, e por alguns segundos parecia não estar presa, mas livre. Movia-se como quem impõe respeito para as demais presas, mas também para as entrevistadoras. Veio ao nosso encontro e afirmou que já tinha participado dessa pesquisa em outra fase. Provavelmente a mulher fragilizada ainda estava ali, mas seria muito mais difícil encontrá-la. Aquele reencontro nos marcou: era a mesma mulher, em duas unidades prisionais distintas e com posturas bastante diferentes.

Mesmo sendo exclusivamente femininas, as duas unidades possuem algumas diferenças importantes entre si. A PIEP foi inaugurada por volta de $1950^{4}$, sendo assim a mais antiga, além de ser a única prisão feminina da capital de Minas Gerais. Desta maneira, as mulheres presas gestantes eram lá alocadas em um pavilhão destinado para tal finalidade. Acontece que, em 2009, com o crescente debate político sobre a situação dessas mulheres, o governo de Minas Gerais inaugurou o CRGPL, tendo como principal objetivo abrigar as gestantes e as presas de todo o Estado que possuíssem filhas/os com até 1 ano de idade. Assim, o Centro foi projetado e idealizado visando à convivência e à assistência à saúde das mães privadas de liberdade e de suas crianças.

É importante pontuar que, apesar das suas particularidades, e mesmo que tenham surgido em momentos diferentes, as duas unidades são resultado de discussões históricas anteriores a elas. Em 1924, Lemos Britto - respeitado advogado da época, que ocupava uma posição de destaque em assuntos penais - propôs a primeira reforma no sistema penal brasileiro, que acabou por se consolidar em 1940. O foco principal dessa reforma foi com relação à alocação de homens e mulheres nos estabelecimentos penitenciários, visto que até então

4 Para uma discussão mais aprofundada sobre a não exatidão desta data, ver: MARTINO, 2019. 
ambos os sexos cumpriam suas penas nas mesmas instituições, não havendo distinção de sexo nos presídios brasileiros (SOARES; ILGENFRITZ 2002).

Diante desse cenário, a proposta de Lemos Britto enfatizava a necessidade da separação de homens e mulheres, uma vez que ambas as instituições deveriam almejar finalidades diferentes: enquanto as prisões masculinas visavam resgatar o sentido de legalidade e trabalho entre os presos, as penitenciárias femininas buscavam reeducar as mulheres dentro da moralidade e dos bons costumes. Por isso, foi proposto um "estabelecimento especial feminino", para que as mulheres tivessem acesso a uma educação especial guiada pelos padrões tradicionais de gênero que não deveriam ser aprendidos em prisões masculinas (SOARES; ILGENFRITZ 2002; PIZOLOTTO, 2014).

Importa-nos, aqui, entender melhor essa expectativa de educação pautada em padrões tradicionais de gênero. Diferentemente do aspecto biológico de sexo, gênero é uma categoria analítica que remete a uma construção cultural que está relacionada a um determinado contexto social e que acaba por orientar "a organização social da relação entre os sexos" (SCOTT, 1989). Assim sendo, falar de papel de gênero é assumir que, devido às diferenças biológicas, há posições distintas para homens e mulheres ocuparem na sociedade. Segundo os padrões tradicionais de gênero, tais como construídos tradicionalmente, cabe à mulher as funções de cuidadora da casa, das/os filhas/os e do marido, ou seja, é designado a ela o ambiente privado como esposa, mãe e dona de casa - ao passo que o lugar do homem, nessa relação, seria o ambiente público, de maior poder e prestígio social (PARSONS; BALES, 1956).

Com o avanço dos estudos feministas, tanto o conceito de gênero como a construção de papéis de gênero baseados no sexo passaram a descortinar as relações de poder e de desigualdade na ordem social. A análise sociológica destaca, nesse sentido, que é através de processos de socialização que homens e mulheres aprendem a desempenhar um determinado papel social. Ou seja, é nesses processos de socialização que se impõem padrões sociais de comportamento, normas, valores e crenças aos indivíduos (BERGER, P.; BERGER, B., 2008).

Foi, portanto, com o objetivo de educar as mulheres criminosas segundo os papéis tradicionais de gênero que as instituições prisionais femininas, edificadas a partir do Código Penal de 1940, passaram a ser coordenadas pelas irmãs da Congregação do Bom Pastor d'Angers (ANGOTTI, 2011). Pizolotto (2014) pontua ainda que, naquele momento, as mulheres consideradas criminosas eram mais aquelas que desafiavam os dogmas religiosos e dividiam 
as concepções morais, sendo acusadas, nesse sentido, de bruxaria à prostituição. Assim, como desviantes das expectativas do papel feminino de "mulher do lar" - ou seja, com apreço às funções domésticas, e caracterizadas como dóceis e devotas religiosas -, nas prisões elas eram obrigadas a se dedicar a trabalhos domésticos, tais como costurar, cozinhar e limpar, para então estarem aptas a retornarem para a sua família e para o convívio social. As mulheres solteiras, idosas ou sem vocação para o casamento estariam, por sua vez, prontas para seguir a vida religiosa.

A Penitenciária Industrial Estevão Pinto surgiu logo após o Código Penal de 1940, e apesar de nunca ter sido administrada pelas irmãs da Congregação, edificou-se no momento de materialização dessas ideias. Com o passar dos anos e décadas, as questões referentes às mulheres presas pareciam invisíveis aos debates políticos, sociais e, em certa medida, acadêmicos (MARTINO, 2019). Elas só começaram a ganhar notoriedade novamente na década de 1990, quando os níveis de encarceramento feminino começaram a aumentar, especialmente, pelo crime de tráfico de drogas. Desde a inauguração da PIEP, várias mudanças marcaram o sistema prisional feminino, como o regimento único independentemente do sexo, que visa à ressocialização e à punição preconizado na LEP (1984), e leis como a de Bangkok (2010), que pontuam a necessidade da atenção pelas especificidades das mulheres em situação de prisão. É nesse contexto que surge o Centro de Referência à Gestante Privada de Liberdade que, mesmo distante temporariamente das discussões iniciais sobre a necessidade de a instituição prisional ensinar a presa a "ser mulher" discussões essas que pareciam ter sido superadas -, traz no discurso de suas profissionais alguns resquícios de um passado que ainda se faz presente.

Posto isso, algumas questões surgem: apesar das modificações pelas quais as prisões passaram, ainda podemos perceber nos discursos os valores do aprendizado do "ser mulher"? Duas prisões femininas podem possuir objetivos diferentes? É possível perceber essas diferenças nas falas de mulheres que têm suas vidas perpassadas por essas unidades? Tais questões nos acompanham desde o encontro e o reencontro com a Paula, lá em 2018. 


\section{Notas metodológicas}

O campo de pesquisa e os dados construídos que compõem este artigo são resultado da pesquisa intitulada "Amor bandido é chave de cadeia?5" idealizada e realizada por uma equipe de pesquisadoras do Centro de Estudos em Criminalidade e Segurança Pública (CRISP/UFMG). O trabalho de campo ocorreu entre o segundo semestre de 2017 e o primeiro semestre de 2018 e abarcou duas unidades prisionais exclusivamente femininas da Região Metropolitana de Belo Horizonte: o Centro de Referência à Gestante Privada de Liberdade (CRGPL) e o Complexo Penitenciário Estevão Pinto (PIEP). A escolha por ambas se deu para que pudéssemos englobar as diferentes vivências das mulheres presas, em momentos distintos de suas trajetórias de vida. Pudemos, com isso, analisar duas experiências de cárcere possíveis para mulheres que são privadas de liberdade.

A primeira fase da pesquisa foi realizada no CRGPL, e lá foram feitas entrevistas com sete internas e cinco profissionais, com a utilização de dois roteiros semiestruturados distintos para os dois grupos de mulheres. O mesmo ocorreu na PIEP, foco da segunda parte da pesquisa, em que foram entrevistadas cinco profissionais e quatro presas, sendo duas do regime fechado e duas do regime semiaberto.

Todas as entrevistas foram gravadas - mediante a autorização e assinatura do TCLE -, a fim de garantir maior fidelidade às falas a nós confiadas. Após a gravação, as entrevistas foram transcritas e analisadas no software N-Vivo. Importante destacar que todas foram realizadas dentro das unidades por duas entrevistadoras e uma entrevistada de cada vez, sem qualquer outra pessoa presente, a fim de garantir o anonimato, como também a segurança e o conforto das entrevistadas para que pudessem manifestar suas opiniões e compartilhar suas experiências.

Tendo em vista a discussão a que nos propomos neste artigo, a principal fonte de análise de dados, sem dúvida, são os relatos trazidos pelas entrevistadas. Desta forma, em nossa análise é dada à perspectiva qualitativa uma maior atenção. Contudo, além das entrevistas, a pesquisa contou com a aplicação de surveys nas duas unidades, o que resultou em 170 questionários respondidos por presas custodiadas na PIEP e 26 no CRGPL - e a diferença do tamanho da amostra condiz com o tamanho e o número de mulheres abrigadas

5 Financiada pela FAPEMIG (APQ-01648-16) e aprovada pelo Comitê de Ética da Universidade Federal de Minas Gerais (CAAE: 84242418.4.0000.5149). 
nas duas unidades. No momento da pesquisa, a PIEP abrigava cerca de 350 mulheres, e o Centro, 50 internas - entre grávidas e mães junto de suas/seus filhas/os. Deste modo, para uma análise mais ampla, em alguns momentos serão utilizados gráficos correspondentes aos dados quantitativos, tratados e analisados no software Excel.

Assim, a análise que segue será eminentemente qualitativa, utilizando tanto os dados construídos a partir das entrevistas feitas com profissionais e presas das duas unidades prisionais visitadas como os demais relatos coletados durante o trabalho de campo. Para a investigação a que se propõe o presente artigo, soma-se a esse esforço a construção de alguns gráficos que dizem respeito aos resultados dos questionários aplicados somente às detentas das duas unidades. Por fim, vale ressaltar que, tendo em vista as particularidades das duas unidades prisionais, a perspectiva comparativa de alguns discursos e dos gráficos apresentados por vezes nos possibilita examinar pontos importantes deste estudo.

\section{Maternidade no cárcere: oportunidade à punição?}

Se, ao analisar o sistema prisional feminino brasileiro, é difícil não pensar sobre maternidade - uma vez que $75 \%$ das mulheres que estão presas têm filhas/os dentro ou fora dos muros das prisões (INFOPEN, 2018) -, quando o campo da pesquisa é em uma unidade materno-infantil, isso se torna praticamente impossível. Como o CRGPL abriga mulheres gestantes e mães com crianças até o primeiro ano de vida, a maternidade é a vivência central, que acaba por definir tanto a rotina como a organização prisional, impactando também os valores compartilhados na unidade.

A unidade materno-infantil foi criada para garantir o direito da criança de ser amamentada e também para que ela e sua mãe criassem um vínculo e mantivessem uma relação mais próxima durante o primeiro período de sua infância. Mesmo que em momentos anteriores e, em alguns casos, em maternidades passadas isso não tenha sido possível. Tendo em vista essa realidade, algumas profissionais afirmavam que a possibilidade de vivenciar o cárcere com suas/seus filhas/os era uma oportunidade singular para muitas dessas mulheres, uma vez que era a primeira vez que elas estavam sendo "mães de verdade". As funcionárias justificavam tal afirmação dizendo que grande parte das internas tinham outras/os filhas/os que conviveram mais com outros familiares do que com a mãe - mesmo quando ela ainda não estava presa. 
Sendo assim, as internas do CRGPL não teriam participado ativamente da criação ou mesmo da amamentação de suas crianças, antes do cárcere.

Pesquisadora: Você acha que as presas, elas conseguem exercer a maternidade dentro do sistema prisional?

Entrevistada: Conseguem, conseguem. Com todas as dificuldades, com todas as limitações. Algumas até conseguem ser mães pela primeira vez, consegue ter... Não é ser mãe. Consegue cuidar, cuidar... É o cuidado. E é ela e o bebê, não tem jeito ela vai ter que cuidar. (Profissional CRGPL 1).

Importante notar que ser mãe está, nessa e nas demais narrativas, relacionado ao trabalho do cuidado, segundo as profissionais do Centro. Assim, a responsabilização da mulher com relação ao cuidado das/os filhas/os remete ao que tradicionalmente definimos como competência de mulher, ou mesmo como lugar de mulher. É, portanto, com vistas à divisão sexual do trabalho que tanto as tarefas domésticas quanto as relações de cuidado são tidas como trabalho feminino (BIROLI, 2018).

Pesquisadora: Você acredita em ressocialização por meio da maternidade?

Entrevistada: Acredito.

Pesquisadora: Por quê?

Entrevistada: Por causa disso mesmo, da proposta de mudança de vida delas de ter essa oportunidade de estar cuidando desse filho, às vezes já teve muitos e não trocou nenhuma fralda, não deu nem o peito. (Profissional CRGPL 2).

Assim, segundo as profissionais da unidade, o tempo na prisão juntamente com sua criança era o momento que estas mulheres teriam para se dedicar integralmente à criança, uma vez que "aqui elas são obrigadas a serem mães 24 horas por dia" 6 . Mais do que dar a oportunidade para que a mãe cuide e conviva com seu filho, o Centro enxerga na maternidade também outra função: a ressocialização. As profissionais do CRGPL, em sua maioria, acreditavam que a oportunidade de se dedicar à maternidade - logo, ao cuidado dos bebês fazia com que essas mulheres tivessem uma nova perspectiva de vida. Tal visão

${ }^{6}$ Fala de uma profissional fora do momento da entrevista. 
nos chamou bastante a atenção e, nesse sentido, a fala de uma das funcionárias entrevistadas se destacou: para ela, se tem um lugar em que é possível pensar em ressocialização dentro do sistema prisional, esse lugar é no CRGPL. Segundo Cunha (2014), apesar das transformações nos objetivos do sistema prisional, as ideias de reabilitação permanecem presentes nos discursos institucionais, sendo mais nítido na prisão feminina o discurso ressocializador ligado ao papel tradicional de gênero, o que é possível perceber tanto pela fala da profissional entrevistada 2, como na entrevista que segue:

Pesquisadora: Você acha que a maternidade exercida dentro do sistema prisional muda a vida dessas mulheres?

Entrevistada: Algumas mudam, não é?! É igual os presos, uns mudam, ressocializam, trabalham honestamente e tem uns que não. Aqui também é assim, umas mudam e outras não, mas quando elas estão aqui com a criança, porque aqui é uma escola. Presa aqui que nunca cuidou de criança, cuida agora porque sempre foram os pais, as mães que cuidavam, não é?! E aqui ela aprende a cuidar da criança, lidar com a criança, entendeu? Ela adquire mais uma experiência e pega mais amor, então por isso também que muitas mudam, muitas saem do crime, entendeu? (Profissional CRGPL 3).

Tendo em vista tais narrativas, entendemos que o discurso sobre aprendizagem - mais do que isso, sobre uma oportunidade de aprendizagem no Centro - remete à expectativa de um determinado papel de gênero. É emblemático, nesse sentido, que uma das profissionais faça uso do termo escola. Embora não estivesse nas normativas, mas tendo a maternidade uma finalidade latente na unidade prisional materno-infantil visitada, observamos o quanto ela está presente no discurso e na prática cotidiana e passa a ser tutelada pela instituição a partir de regras que vão interferir tanto na relação da mãe com a criança, como na educação de suas crianças. Para Braga e Angotti (2015, p. 235), unidades como o CRGPL são caracterizadas "pelo rigor disciplinar e tutela do exercício da maternidade". Ou seja, nesses contextos, as mulheres são submetidas às regras da unidade também no âmbito do exercício da maternidade. Regras estas que são impostas, muitas vezes, sem nenhuma justificativa.

Se, por um lado, as profissionais do Centro enfatizaram a importância das regras da unidade para que as mulheres exerçam sua maternidade - o que nos remete ao rigor disciplinar de uma escola -, as mães entrevistadas demonstraram insatisfação com o excesso de normas às quais sua maternidade 
está submetida. Algumas delas são: se o filho chorar por muito tempo, as mães recebem comunicado - um tipo de advertência -, todas as mulheres são obrigadas a amamentar por um período determinado, mães não podem dormir na cama com a sua criança ou deixá-la andar no chão, e as internas são obrigadas a levar seu filho para todos os lugares - inclusive para os locais em que realizam a limpeza.

De acordo com seus relatos, apesar de não concordarem com essas regras, as internas obedecem a elas, porque um comunicado pode trazer atrasos significativos em seu processo. Assim, elas seguem vivendo uma "maternidade desautorizada" (DIUANA et al., 2017). Tendo isso em vista, a maternidade exercida em uma unidade prisional materno-infantil é perpassada por diversas privações, angústias e normas para as mães, e isso é incontestável. Enquanto isso, na perspectiva das profissionais da instituição, para além dessa realidade - que não é negada -, destaca-se uma outra: a oportunidade de "ser mãe verdadeiramente" como uma possibilidade de ressocialização a partir do exercício materno.

Tais conclusões, com a pesquisa realizada no CRGPL, não encontram ressonância nos resultados coletados na outra unidade prisional feminina também analisada. Na PIEP, falar sobre maternidade com as profissionais resumiu-se a tratar das visitas que as mães podem receber de suas/seus filhas/os aos domingos e, por outro lado, na ausência das mães na vida de suas crianças - anteriormente a sua prisão, inclusive. Se no Centro parte das profissionais acreditavam na ressocialização por meio da maternidade, na PIEP essa pergunta era sempre respondida com uma negativa. As justificativas eram quase uníssonas: a grande parte das mulheres encarceradas na PIEP já eram mães, e isso não as impediu de serem reincidentes e retornarem à prisão, de acordo com as profissionais.

Além disso, as profissionais da PIEP acionaram a mesma narrativa utilizada pelas funcionárias do CRGPL sobre as mulheres presas não terem vivenciado a maternidade anterior ao cárcere em sua integralidade. Isso por não se dedicarem ao cuidado de suas/seus filhas/os, por possuírem um contato restrito com elas/es, ou por muitas das presas não morarem junto das/os filhas/os antes da prisão. Buscando aprofundar nessa questão, com o Gráfico 1 a seguir podemos mensurar quantas/os filhas/os viviam com as mães antes do aprisionamento. De acordo com o survey aplicado nas duas unidades, temos os percentuais da análise quantitativa de forma comparada. 


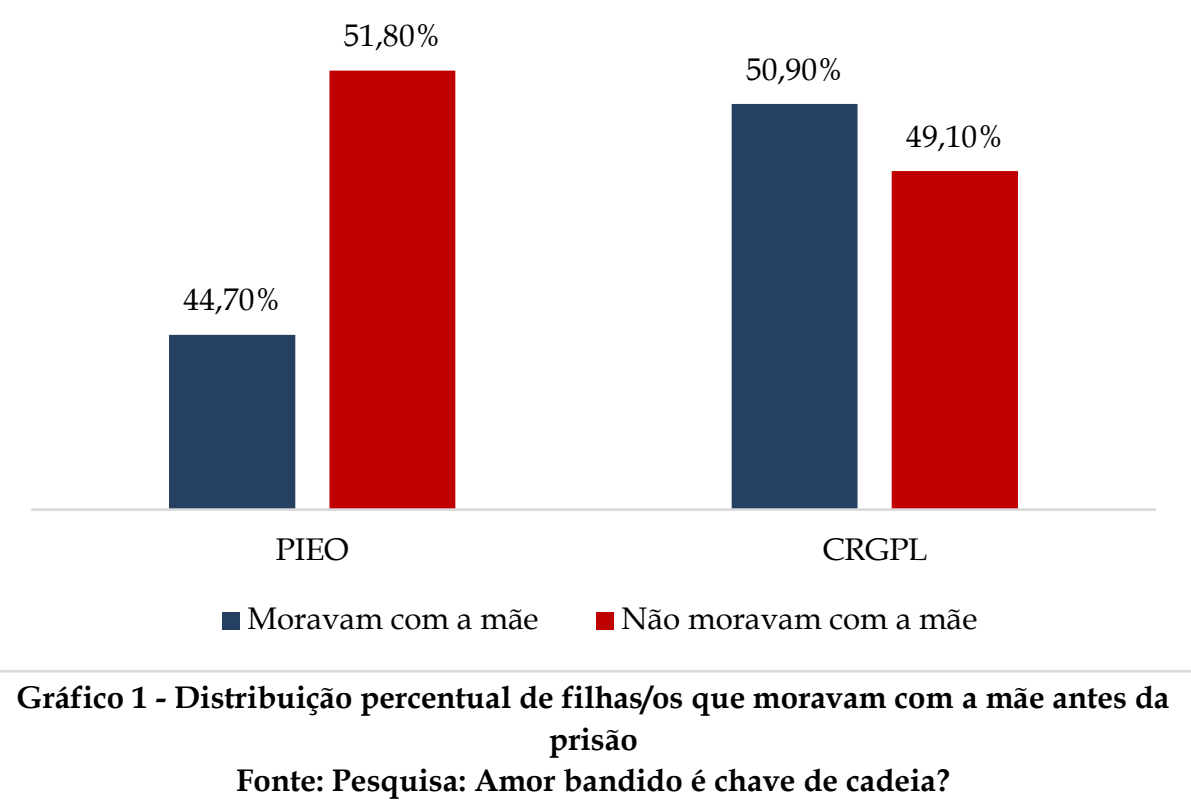

O gráfico, apesar de apresentar percentuais bastante parecidos entre si, demonstra uma diferença entre as presas da Estevão Pinto e as do Centro de Referência. Enquanto na primeira unidade a maioria das/os filhas/os não residiam com a mãe, na segunda acontecia o inverso. Granja et al. (2012) já tinham atentado para essa realidade, pontuando que as mulheres encarceradas antes mesmo da prisão contavam com uma importante rede de apoio e que, muitas vezes, a moradia de suas crianças era delegada a essas redes. Contudo, como destacam as autoras, isso não as impedia de contribuir para o cuidado de seus filhas e filhos - com a ressalva de que, às vezes, até mesmo abrir mão da presença constante das/os filhas/os é uma forma de garantir um maior bemestar a elas/es. As autoras argumentam ainda que na prisão essas mulheres são rotuladas como "mães ruins" e aceitam para si tal rótulo, sentindo-se culpadas pelo tempo que não passaram com suas/seus filhas/os (GRANJA et al., 2012).

Com a pesquisa na PIEP pudemos notar algo bastante similar: também consideradas "mães ruins" pelas profissionais da unidade, o discurso mais recorrente das entrevistadas era de que as mulheres mães presas diziam se importar ou mesmo sentir falta de suas crianças apenas enquanto cumpriam pena de privação de liberdade, mas, quando saíam da prisão, nem sequer as/os viam, preferindo estar em outros lugares. Segundo as funcionárias entrevistadas, da mesma forma que as mulheres mães não cuidavam das 
filhas/os antes da prisão, não cuidariam depois. Desta maneira, os relatos de culpa e arrependimento que as presas traziam eram, para elas, apenas um discurso vazio e momentâneo.

Pesquisadora: Você acredita em ressocialização por meio da maternidade?

Entrevistada: Para ser sincera? Não. Tem casos que pode acontecer? Tem, mas na maioria dos casos, principalmente os que envolvem a dependência química, eu acho que não. A gente tem um histórico muito grande de a criança, mesmo antes do processo de encarceramento, estar distribuída entre os familiares, crianças que estão em acolhimento institucional, e aqui a gente consegue caminhar até para programa de laqueadura. Tem sete filhos, às vezes mal criou nenhum, a gente tenta a laqueadura ou a conscientização até de outros métodos que são legais. Ela ainda tem esperança do homem, do filho, de constituir família e tirar ela daquela situação, agora elas voltam para esses homens, elas acabam arrumando filhos e prisões. Então, a minha visão particular é que só a maternidade não, até porque muitas têm problemas, apesar de terem muitos filhos, elas já cumpriram esse papel social de mãe desde antes do processo de encarceramento. Já tem um histórico, não vou dizer de abandono, porque nem sempre elas abandonam, mas de um não cuidado com os filhos. Normalmente, ela passa essa responsabilidade de cuidar do filho para o familiar mais próximo, aí é a mãe que cuida, é o avô, e elas mesmo ficam às vezes sem contato, às vezes não. Acabam tendo filhos e não se responsabilizando pelos cuidados deles, passando para outro familiar. Então eu, particularmente, eu não acredito (Profissional PIEP 2).

As mulheres presas também se pronunciaram acerca das diferenças entre as suas formas de maternar, sobretudo com relação à dedicação com o cuidado das/os filhas/os. Isso significa dizer que, ao invés de rechaçarem e resistirem ao ideal burguês de maternidade integral, as mulheres mães presas, ao serem rotuladas como "mães ruins" ou ainda "menos mãe", internalizam, muitas vezes, o rótulo dado pelas funcionárias da instituição. Assim, passam a identificar a sua experiência materna a partir de uma noção de maternidade dominante que, vale enfatizar, é idealizada (BADINTER, 1985) e muitas vezes incompatível com a realidade de mulheres pobres e trabalhadoras independentemente do envolvimento ou não delas com atividades ilegais. É nesse sentido que muitas das internas entrevistadas no CRGPL remetem às suas experiências como mãe em uma perspectiva comparada. 
Entrevistadora: E você acha que o seu vínculo com ela [a criança que a interna tinha nos braços] é diferente do seu vínculo com os seus outros filhos então?

Entrevistada: É. Eu amo todos iguais, mas o carinho assim eles não tiveram o carinho que ela está tendo, não é?!

Entrevistadora: E como que está sendo para você essa experiência? Porque você falou que agora é a primeira vez que você está cuidando mesmo.

Entrevistada: Eu falo com a senhora, Nossa Senhora, eu me arrependo de não ter feito isso com os outros. Tem hora que eu sento que eu peço "Deus, perdão" porque... Eles uma hora vão jogar na minha cara quando "Ah ela foi cuidada e a gente não foi, por quê? O que aconteceu? "Eu não vou mentir, mas eu me arrependo.

\section{Entrevistadora: É?}

Entrevistada: Porque é tão triste me ver dando todo amor e carinho para ela que eu não dei para nenhum dos meus filhos.

Entrevistadora: Mas você está gostando dessa experiência de ficar?

Entrevistada: Ah! Estou demais, um pouco com a consciência pesada, não é?! Por causa dos outros... (Presa CRGPL 6).

Desse modo, os discursos presentes nas instituições prisionais visitadas sinalizando rotineiramente quão péssima mãe a mulher presa foi (e é) faz com que ela não apenas aceite essa realidade, como também faz com que ela sofra e se envergonhe. Afinal, há algum aprendizado sobre ser mulher maior que esse na nossa sociedade? Há uma ideia de que toda mulher tem vocação para maternidade, de que a boa mulher corresponde ao ideal de boa mãe e de que toda boa mãe se realiza na dedicação integral à maternagem, se devotando e se sacrificando voluntariamente pelo filho (SCAVONE, 2001; VÁSQUEZ, 2014; RESENDE, 2017). Tudo isso nos remete à obra de Beauvoir (1949), que enfatiza como o processo de socialização é fundamental para que a mulher se encaixe no padrão de gênero imposto pela sociedade. Assim como Beauvoir (1949) trata da aprendizagem para tornar-se mulher, Badinter (1985) discorre sobre o processo histórico e social que consolida a forma ideal de exercer a maternidade. De acordo com a autora, para se tornar uma boa mãe, a mulher deve corresponder às expectativas sociais tanto da dedicação integral ao 
cuidado como da devoção à vida dos filhos e das filhas, mesmo que isso signifique consideráveis sacrifícios na sua própria vida.

Por fim, outro ponto que se destacou nas entrevistas realizadas foi com relação às visitas das/os filhas/os às mães presas. Como não cumprem sua pena com suas/seus filhas/os, as profissionais da PIEP ponderam que a principal forma de manter algum vínculo materno é através das visitas. Uma das entrevistadas conta que durante um tempo as visitas assistidas ${ }^{7}$ eram mais frequentes e contavam com atividades, doações e brincadeiras para as crianças, mas com o tempo se tornaram mais escassas e com algumas proibições. $\mathrm{Na}$ ocasião, a entrevistada endossou a necessidade de proibições, porque, segundo ela, as crianças precisavam saber desde pequenas que a prisão não é "um bom lugar", levantando, inclusive, o argumento de que a homossexualidade é comum dentro dos cárceres femininos. Ainda que raramente, tais ações - que a funcionária denomina visita assistida - para as mulheres mães presas e suas/seus filhas/os ainda aconteciam na unidade e eram, em grande medida, fundamentais para manutenção do vínculo e do contato entre eles, uma vez que as visitas semanais eram raras tanto nesta unidade como na unidade materno-infantil.

Como argumentam Becker et at. (2016), a ausência de visitas faz referência a uma forma de dupla sanção no cárcere: formal e social. Para as profissionais entrevistadas no CRGPL e na PIEP, é fato que as mulheres recebem menos visitas em comparação com os homens presos. Em nossas entrevistas, tanto com as mulheres presas quanto com as funcionárias das duas unidades, essa ausência de visitas se justifica por três motivos: a distância da unidade prisional, a vulnerabilidade social em que vivem as famílias das presas, e pelo abandono que normalmente sofrem as mulheres na prisão. Vale ressaltar que, no caso do CRGPL, a falta de visitas é ainda mais agravada pelo fato de a unidade receber gestantes e presas de todo o Estado. Essa escassez de visitas é fundamental para compreender também outra questão: a sexualidade e afetividade dentro dos cárceres femininos.

7 Visita agendada, fora dos dias já convencionais, entre mãe e filha/o que é acompanhada pela assistente social e/ou psicóloga. 


\section{Mulher e sexualidade: uma privação necessária?}

Presas e profissionais das duas unidades afirmaram que mulheres eram menos visitadas quando estavam presas, e o contato com o mundo externo se dava por carta, por telefone e por SEDEX - no caso das famílias que tinham condições financeiras para enviar produtos de subsistência, como itens de higiene, principalmente.

Entrevistada: As visitas de homens vão a mulher, vai a mãe, vai a irmã, vai a prima, é um tal de prima de tudo quanto é lado, que na verdade são todas amantes. E da mulher... Geralmente o companheiro que visita é o companheiro que já foi preso, porque ele sabe do sofrimento da prisão, ele sabe da solidão, de tudo que ruim que a prisão tem, aí ele costuma vim, o que já foi preso. O que não foi, eles têm mil argumentos: "ah! Porque eu não vou dar conta de te ver lá", "ah! Porque muito sofrido", "ah por isso, porque aquilo", e elas ficam, não é?! Nesse momento de tanto sofrimento eles pulam fora. (Profissional CRGPL 1).

Casos de relacionamentos que acabavam quando as mulheres eram presas foi o que mais ouvimos durante as entrevistas com as internas das duas unidades, que diziam: "homem não marcha junto com mulher", "só mulher que paga cadeia com homem". Assim, a escassez de visitas de familiares, filhas/os e companheiras/os resulta em um sentimento de solidão e abandono dentro da prisão, como nos foi relatado por elas. E desse cenário, as profissionais acreditam surgir uma grande carência das mulheres que, em alguns casos, procuram saná-la em relacionamentos com outras companheiras da prisão. Essa situação foi abordada no survey, quando as presas foram questionadas se era comum mulheres se relacionarem afetivamente no cárcere (Gráfico 2). 


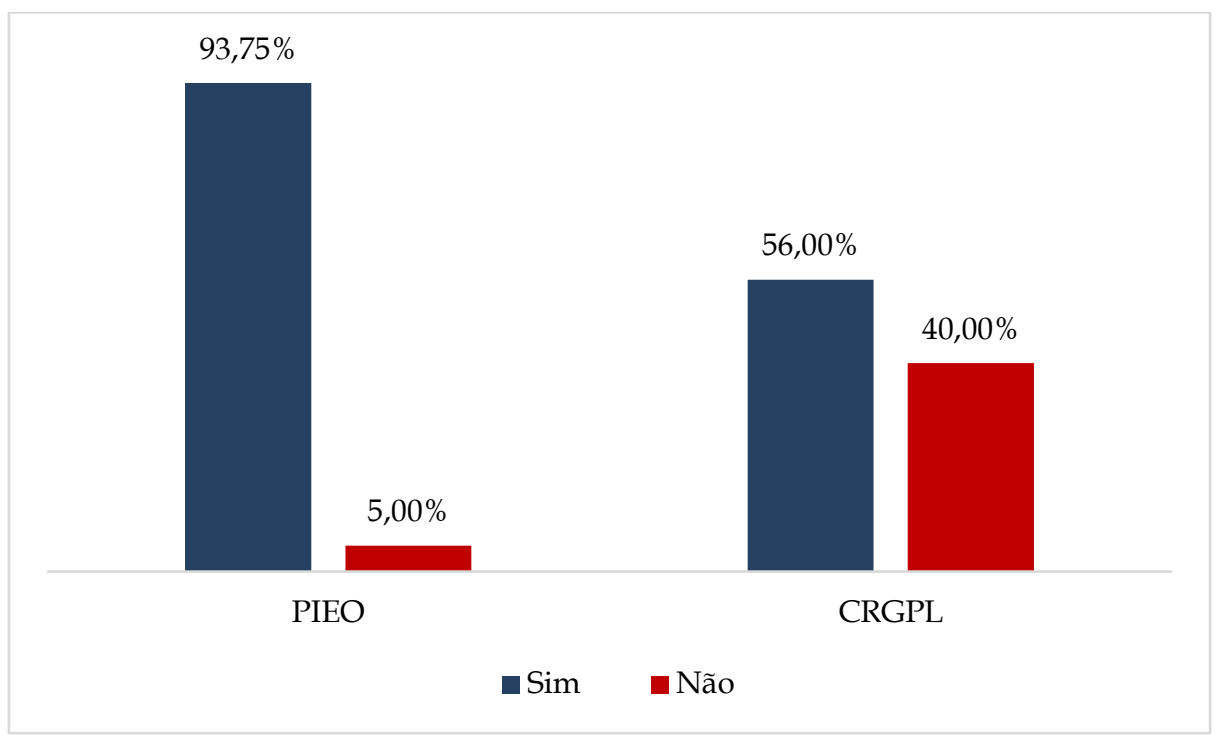

Gráfico 2 - Distribuição percentual da crença das presas sobre ser ou não comum a relação afetiva entre mulheres na prisão

Fonte: Pesquisa: Amor bandido é chave de cadeia?

Interessante notar que a diferença percentual mencionada entre as presas da PIEP é consideravelmente maior em relação àquelas do CRGPL. Isso nos indica que, de alguma forma, essa realidade é mais relatada na Estevão Pinto. Essa diferença foi notada também nas entrevistas com mulheres profissionais e presas da PIEP, em que a exposição dos relacionamentos homoafetivos eram mais comuns no cotidiano da prisão e tratados sem sequer as entrevistadoras terem citado o tema. Ocorre, por exemplo, que as profissionais consideram as brigas de casais um dos principais problemas da unidade. Isso foi mencionado diversas vezes seguido da frase "você sabe como é mulher, não é?". E foi também na PIEP que uma das detentas entrevistadas afirmou que se relacionava com uma companheira da unidade, o que não aconteceu em qualquer momento das entrevistas realizadas no Centro.

Pesquisadora: E que tipo de coisas que elas demandam, o que elas mais demandam, você falou quando não recebe doação, esse que tipo de demanda que chega mais em vocês?

Entrevistada: A maioria elas vão brigar por causa de mulher.

Pesquisadora: Entre elas mesmas? 
Entrevistada: Quando muda, igual, quando há remanejamento de setor, tira uma namorada coloca em outro lugar, aí a outra fica doida, bomba, a maior parte das brigas é de namoradas. Porque o homem abandona mulheres, são pouquíssimas que recebem visita íntima de homem, ali são as suítes. (Profissional da PIEP 4).

Temos uma hipótese para essa diferença: no Centro há uma restrição ao prazer sexual formal e informal associado ao momento idealizado da gestação e maternidade. Braga e Angotti (2015) demonstram, com seus estudos, que as mulheres que se encontravam em unidades materno-infantis pagavam um alto preço quanto à negação do seu direito sexual e reprodutivo em troca da presença de sua/seu filha/o. Essa realidade salta aos olhos no CRGPL. Como exemplo, podemos citar que, ao serem questionadas sobre a visita íntima, as profissionais do Centro diziam que na unidade ela não acontecia, porque a estrutura da unidade não comportava, mas também porque "não era o momento" - mesmo que fizesse falta às internas. As narrativas das profissionais sinalizavam, assim, para um rompimento obrigatório da sexualidade com o advento da maternidade. Segundo a maioria das funcionárias entrevistadas, como as mulheres estavam ali para cumprirem sua pena e exercerem o papel de mães, não condizia com essa realidade o exercício da sexualidade.

As profissionais da PIEP, por outro lado, demonstravam que a questão que dificultava o acesso das mulheres à visita íntima era a prisão ou o abandono do companheiro. Como para ter direito à visita a mulher deveria estar em uma união estável comprovada, a ausência do parceiro anterior à prisão significava a impossibilidade do exercício de sua sexualidade formalmente. Uma das profissionais entrevistadas relata que apenas sete das quase quatrocentas detentas da unidade tinham a liberação para a visita íntima, sendo que duas delas eram entre presas da própria instituição. Mas o exercício da sexualidade entre as presas não é dependente da liberação formal, assim as mulheres conseguem exercê-la de forma informal dentro de suas celas, e isso é de conhecimento de todas as profissionais. Ainda com relação aos dados coletados no survey aplicado às detentas, aquelas que responderam que era comum mulheres se relacionarem na prisão (Gráfico 2), também foram questionadas sobre quais eram os motivos, de acordo com a sua opinião, que fazem com que as presas se relacionem uma com as outras. 


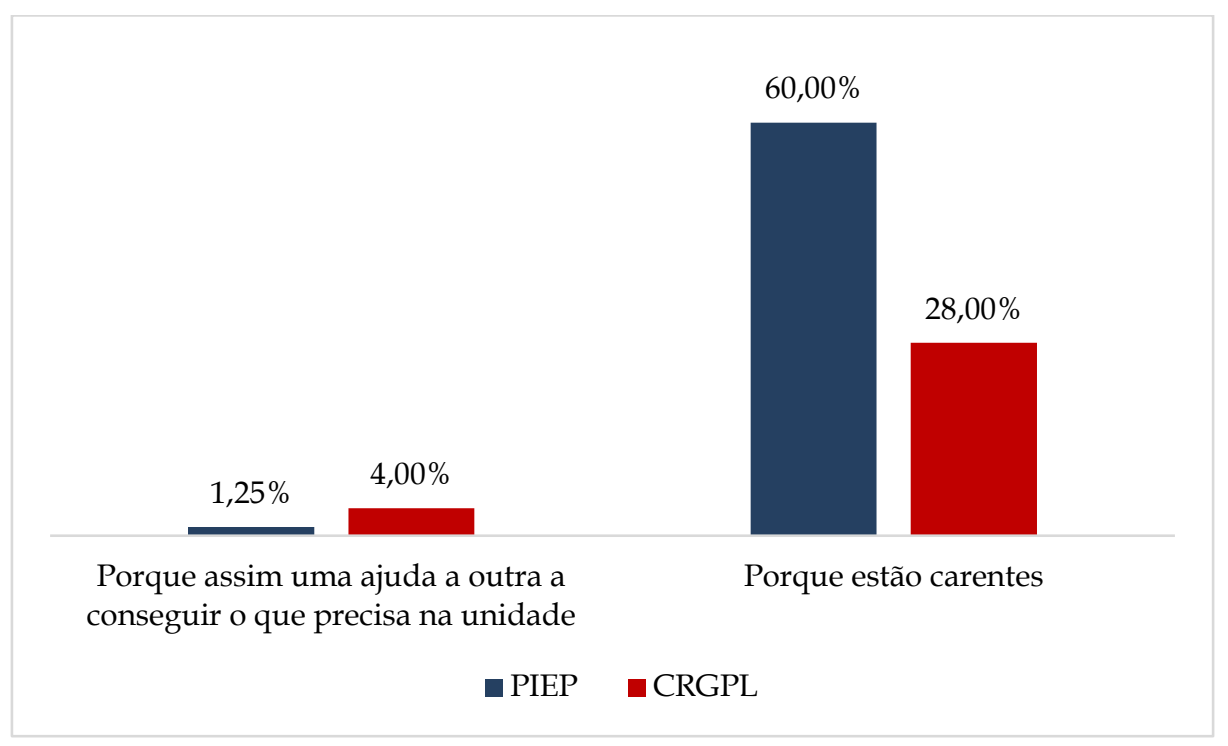

\section{Gráfico 3 - Distribuição percentual dos motivos que levam as presas a se relacionarem dentro da prisão \\ Fonte: Pesquisa: Amor bandido é chave de cadeia?}

O Gráfico 3 demonstra que a maioria das mulheres acreditam que esses relacionamentos são frutos das carências afetivo-sexuais, isso em ambas as unidades. Por sua vez, a ajuda entre elas aparece como uma motivação com percentuais bastante pequenos. No Centro, $4 \%$ das mulheres ainda relataram a paixão como um potencializador desses envolvimentos, e é interessante notar que o sentimento é apenas usado como justificativa nessa unidade, onde o amor é constantemente exaltado como uma forma possível para mudança de vida. Dentre as opções apresentadas existia a opção "outros" - que representou uma porcentagem consideravelmente alta em ambas as unidades - em que as detentas relatavam algo além dos motivos que compõem o gráfico. Na PIEP, as respostas giravam em torno do desejo, da oportunidade de exercerem a homossexualidade, da curiosidade, da decepção e da desilusão amorosa, como também da orientação sexual assumida antes do cárcere. Já no Centro, para além da justificativa da paixão, nesse campo apareceram três tipos de respostas: "não sei", " doidera", "inventando moda".

Mesmo sendo compartilhada por funcionárias entrevistadas do Centro e da PIEP, e tendo uma grande consonância com a literatura sobre o tema (CUNHA, 1991; BARCINSKI, 2012), a crença na homossexualidade dentro do cárcere apenas como um fruto da carência afetiva-sexual e material não abarca a complexidade de motivos que podem levar a relações homoafetivas dentro da 
prisão. Em um contexto de muitas privações, são diversas as justificativas para que as mulheres se relacionem. Para além da carência, o interesse também aparece como motivo em entrevista com uma das presas:

Entrevistadora: Existe a ideia de que as mulheres presas se relacionam mais entre elas, em relacionamentos homossexuais, isso é verdade?

Entrevistada: Sim.

Entrevistadora: É? E você acha que é porque é por carência, porque precisa de alguma coisa da família da outra que traz, como que é?

Entrevistada: Também, muitas são pelo interesse.

Entrevistadora: Que tipo de interesses?

Entrevistada: Porque eu fico com fulana e ela vai trazer um Sedex para mim, ela coloca minha sacola, ela coloca tudo, geralmente eu acho muito pelo interesse.

Entrevistadora: A maioria é por isso?

Entrevistada: É. (Presa PIEP 2).

A carência das mulheres presas parece ser, portanto, apenas uma justificativa aceitável no senso comum para que mulheres se relacionem umas com as outras de forma passageira. Isso é, de certo modo, compartilhado por profissionais e presas das duas instituições prisionais visitadas, dado os resultados do survey aplicado às detentas e das entrevistas com profissionais da unidade. Nesse sentido, o que esteve bastante presente nos discursos das funcionárias entrevistadas foi a ideia de que essa escolha - em última instância, vista até mesmo como um desvio - logo deverá ser corrigida, na primeira oportunidade em que essas mulheres estiverem livres. Ou seja, na ausência de um parceiro, acredita-se que pode haver uma substituição momentânea para curar as carências femininas em um contexto de privação.

Temos que, ao tutelar a maternidade e a sexualidade das mulheres presas, o Estado reafirma os valores sociais e as expectativas do "ser mulher" na sociedade, através das instituições penais analisadas. Mulheres devem ser mães que exercem sua maternidade de forma regrada, disciplinada, devotada e integral e, sendo assim, a sexualidade no CRGPL é tida como menos 
importante ou até mesmo inexistente, uma vez que a relação com a/o filha/o é vista como totalizante.

Por outro lado, na PIEP, uma unidade sem gestantes e mães acompanhadas de suas crianças, as manifestações não heterossexuais de afeto e sexualidade só são minimamente aceitáveis se forem transitórias, uma vez que a "carência" inerente às mulheres não as deixaria cumprir sua pena sem se envolver amorosamente com outras detentas. O que remete também à ideia de que a mulher é, na sua essência, um ser passional. Além disso, o aprendizado do trabalho, as ações de beleza e as narrativas sobre o cometimento do crime são também importantes fontes da compreensão do "ser mulher" no cárcere.

\section{"0 ser mulher": bela, recatada e do lar}

Em 2016, a revista Veja lançou uma matéria sobre a primeira dama do então presidente Michel Temer ${ }^{8}$. A manchete, ao descrever Marcela Temer, sumarizava de forma objetiva as expectativas sociais em relação às mulheres. De acordo com a matéria, que teve grande repercussão na época, elas devem ser belas, recatadas e do lar. Como demonstrado na introdução, (res)socializar as mulheres desviantes dentro dessas normativas, ensinando-lhes funções que eram de sua responsabilidade segundo o tradicional papel de gênero, era a principal função das prisões femininas no momento do seu surgimento e, em certa medida, isso continua acontecendo.

Tanto no CRGPL quanto na PIEP, as funções de limpeza da unidade são todas realizadas pelas presas, que devem manter o ambiente limpo e organizado. Por mais que pareça ser uma norma de boa convivência, as internas do Centro se queixavam da frequência das faxinas que deveriam realizar, além de ser um trabalho que não conta para a remissão de pena. A limpeza da unidade era distribuída entre as internas de acordo com o horário das escalas: às $07 \mathrm{~h}$, às $12 \mathrm{~h}$ e às $18 \mathrm{~h}$. Como foi mencionado, no momento da limpeza da unidade, as crianças estão juntas, porque as internas só são autorizadas a se separarem de suas/seus filhas/os quando vão para o trabalho remunerado. Esse cenário é preocupante pelo fácil acesso aos materiais tóxicos de limpeza e pela presença de bebês em locais insalubres, sobretudo nessa frequência.

Mas, para além da rotina "exaustiva" de limpeza - como nos relataram as internas entrevistadas na pesquisa -, é nos discursos das profissionais que

${ }_{8}^{8}$ Disponível em: https://veja.abril.com.br/brasil/marcela-temer-bela-recatada-e-do-lar/. 
questões cruciais das expectativas de gênero ficam claras. Uma das profissionais do CRGPL, ao nos apresentar as instalações da unidade, ponderou: "como aqui é um lugar de mulheres, a gente exige que seja muito bem organizado e limpo, é muito feio mulher desorganizada". Assim como nesse episódio, em diversas narrativas das profissionais do Centro a importância do trabalho doméstico era ressaltada, remetendo sempre às expectativas relacionadas ao tradicional papel de gênero, que responsabiliza as mulheres pelo - e as aprisiona ao - ambiente privado.

Claro que nas duas unidades visitadas há outros tipos de trabalhos que são remunerados e/ ou que contam para a remissão de pena. Na PIEP, por exemplo, os postos de trabalho são em fábricas de bijuteria, embalagem, roupa, biscoito, artesanato e costura. Já no CRGPL há possibilidades de trabalho na cozinha, no lactário, no artesanato e na costura, além da ocupação de mulheres gestantes, como babás das crianças daquelas internas que trabalham nesses postos. Tais postos de trabalho possuem consonância com o ser "do lar", sendo trabalhos que podem ser compreendidos como a extensão da vida doméstica e, tendo em vista a divisão sexual do trabalho, são considerados como trabalhos femininos (HIRATA; KERGOAT, 2007). Os trabalhos disponibilizados nas duas unidades remetem às primeiras penitenciárias femininas, que viam em atividades similares a oportunidade de socializar as mulheres para os papéis que a sociedade esperava que elas exercessem fora dos muros das prisões.

Outro ponto central em parte das ações do sistema prisional feminino é o tema da beleza, ou seja, da aparência da mulher. Temos, como exemplo, os concursos de miss que ocorrem em Minas Gerais com participantes de todas as unidades do Estado. Em um nível menor, as duas unidades analisadas contavam com o "dia da beleza" no calendário institucional. Nesses dias as mulheres privadas de liberdade tinham a oportunidade de cuidar do cabelo, das unhas e da pele. Para uma das profissionais entrevistadas, a restrição da feminilidade corresponde a uma grande perda para a mulher que está presa, e esses eventos são supervalorizados nas unidades.

Por fim, além de bela e do lar, uma mulher precisa aprender a ser recatada, segundo os padrões tradicionais de gênero. Dentre outras definições, a mulher recatada seria aquela que zela e/ou protege sua reputação e que não ostenta as suas qualidades, sobretudo em relação aos homens - aqueles que desempenhariam o papel social de maior poder e prestígio no ambiente público. Para analisarmos tal perspectiva, é necessário observarmos as narrativas sobre o que leva as mulheres a cometerem delitos. 
Parte da literatura (PIMENTEL, 2008; BARCINSKI, 2009; FIORAVANTE; SILVA, 2011) considera que as mulheres se inserem no crime, principalmente no comércio de drogas ilícitas, influenciadas por homens com que têm envolvimento - sobretudo por aqueles com quem se relacionam amorosamente. Essa constatação foi rotineiramente apresentada pelas profissionais durante as entrevistas como uma justificativa.

Pesquisadora: E você acha que as mulheres, elas se inserem no tráfico por influência de algum homem?

Entrevistada: Muito.

Pesquisadora: É recorrente elas contarem isso para vocês?

Entrevistada: Sim, sim [...] E muitas delas normalmente trazem a história de vida para a gente. Igual, por exemplo, o tráfico, às vezes a mulher entra, usa a vagina como, são mulas, não é?! [...] E acabam sendo presas, e os homens usam disso, sob ameaça de matar filho, principalmente excompanheiros, matar filho, matar parente. Mulher fica doida, aí entra mesmo, então tem sim. (Profissional do CRGPL 4)

A fim de respondermos a tal questão, o survey aplicado tinha uma parte destinada apenas às mulheres sentenciadas pelo crime de tráfico, e lá elas eram questionadas sobre uma suposta influência de homens na sua inserção na vida criminosa. As respostas são apresentadas a seguir no Gráfico 4. 


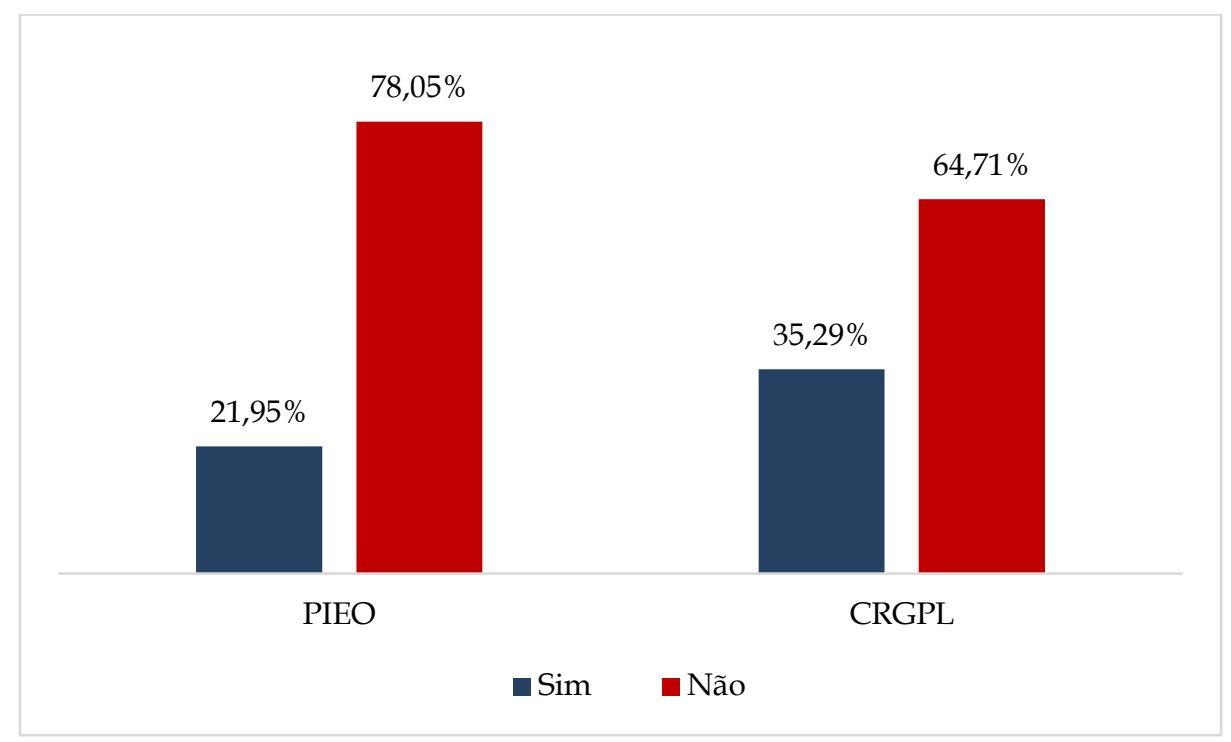

Gráfico 4 - Distribuição percentual de mulheres, acusadas de tráfico de drogas, que acreditam ou não terem entrado no crime por influência do homem

Fonte: Pesquisa: Amor bandido é chave de cadeia?

Contrariando parte da literatura e a visão de algumas profissionais, nas duas unidades as mulheres - em sua maioria - afirmaram que não ingressaram no tráfico por influência de algum homem. Mas, apesar disso, existem diferenças percentuais consideráveis: as mulheres do Centro demonstram uma maior possibilidade de afirmarem que a influência masculina foi um fator importante para o ingresso no mercado de drogas ilícitas, enquanto na PIEP essa afirmação é 14\% menor. Em consonância com o que foi apresentado pelos dados quantitativos, apesar de o argumento da influência masculina estar presente nas justificativas de profissionais e internas das duas unidades prisionais femininas aqui analisadas, é possível perceber sutis nuances do mesmo discurso.

Entrevistadora 01: Entendi... Em sua opinião, a mulher cai no tráfico por causa do homem?

Entrevistada: Acho que sim... A maioria, não todas.

Entrevistadora 01: Não todas. Para você... Qual é o principal motivo que leva as mulheres à prática de algum delito? 
Entrevistada: Algumas vão por causa de influência e outras porque gostam mesmo.

Entrevistadora 02: Mas você acha que tem uma maioria? Assim... A maioria vai por influência ou a maioria vai porque pensa que é uma boa forma de ganhar dinheiro...

Entrevistada: A maioria vai porque pensa que é uma boa forma de ganhar dinheiro.

Entrevistadora 01: E no seu caso?

Entrevistada: Eu fui por influência.

Entrevistadora 02: Mas foi influência? Você falou que ele não te pressionou...

Entrevistada: Não, não me pressionou. Mas eu ia junto. Mas se eu não tivesse com ele, eu não iria. (Presa 3 CRGPL).

Acontece que nas entrevistas com as internas a medida da influência não é algo sempre claro. Na opinião da interna do Centro citada, a maioria das mulheres entram no crime por causa do dinheiro, mas ela aciona a influência do companheiro como principal motivação no seu caso. O contrário também esteve presente nas entrevistas realizadas nas duas unidades: mulheres presas que afirmam ter entrado no crime por decisão própria, mas acreditam ser maioria as que entram por causa da influência de algum homem. De todo modo, mesmo opinando sobre a influência de homens com relação à entrada no crime de outras mulheres, quando questionadas no survey, a maioria das respondentes sentenciadas pelo crime de tráfico de drogas afirmam ter tido agência na sua entrada na vida criminal.

Já as profissionais entrevistadas no CRGPL consideram exceção as mulheres que entram para "o mundo do crime" por vontade própria: para elas, o mais comum é a influência de um homem, e até mesmo o desconhecimento da atividade ilegal de seu companheiro. Um ponto de vista que reitera a posição da interna (presa 03) entrevistada e compõe as narrativas compartilhadas na unidade.

Já na PIEP acontece o oposto: as profissionais da unidade acionaram o discurso de influência masculina pontuando que isso representa alguns casos, mas destacam que existem mulheres com forte liderança na vida criminosa. As entrevistadas citaram casos em que mulheres presas são mandantes de crime, 
casos em que mulheres coordenam o tráfico na sua região, e até mesmo casos de muitas mulheres que cooptam homens para a realização de delitos. Assim, as funcionárias da PIEP tendem a ressaltar a agência da mulher nos trabalhos ilegais e ponderam que isso é mais comum do que se imagina, ou que normalmente se fala.

Entrevistada: Mas a mulher que eu vejo aqui não é essa mulherzinha que é pintada por aí não, sabe muito bem o que está fazendo não foi levada por ninguém: "ah, eu estou com ele, fiquei com ele um ano e não sabia que ele mexia com droga", porque já vai morar junto assim rápido, já está morando junto e você não sabe? "Ah ele saia", "trabalhava com o quê?" "Ah, não sabia com o que ele trabalhava, ele trazia um dinheiro para casa". Sabe aquela coisa assim, "Dona Bete, deixa eu falar que eu fazia vista grossa" ... Agora tem umas que falam: "eu que quis mesmo, eu queria dinheiro queria comprar sapato", tem um negócio de comprar sapato também, coisa de mulher, não é?! Coisa de mulher..." (Profissional da PIEP 1, nome fictício).

Tais narrativas nos chamaram atenção, e a fala de uma das profissionais do Centro nos ajuda a entender as diferenças dos relatos analisados. Segundo ela, as internas do CRGPL enfrentam com maior intensidade o estigma de presa e criminosa, visto que não é esperado de uma mulher a agência no crime, sobretudo porque esse papel se contrapõe - ou se destoa - do papel de mãe que, naquela unidade, elas desempenhavam como papel principal. Diante das discriminações e das sanções morais vividas no CRGPL, o discurso da influência poderia, em alguma medida, ser acionado pelas internas como um recurso para minimizar o estigma sofrido. De acordo com a funcionária, justificando sua vida no crime por meio da influência de um homem, as mulheres presas assumem a posição esperada de uma mulher fiel e leal que ocupa o lugar que o companheiro lhe designou. Nesse sentido, talvez, se tivéssemos entrevistado Paula na PIEP, a versão narrada fosse um pouco diferente, e ela poderia ter sido a protagonista de sua história. 


\section{Considerações finais}

Diante do exposto, concluímos que a experiência de ser mulher no cárcere envolve sobremaneira as expectativas sobre o que é ser mulher na nossa sociedade. E, nesse sentido, há aprendizados específicos que são direcionados às mulheres desviantes e criminosas pelas instituições prisionais, embora com algumas particularidades nas unidades visitadas - sendo o momento de vida da mulher que se torna mãe um marco divisor para os discursos acionados e das normas implantadas, como visto.

De maneira geral, a maternidade é acionada como um aprendizado mais central no Centro, segundo as narrativas analisadas. Todavia, em ambas as unidades há a crença de que apenas a maternidade vivida com uma dedicação integral e devotada poderia transformar a vida de uma mulher criminosa e afastá-la das práticas ilegais. Esse pressuposto faz com que no Centro a crença pela ressocialização através da maternidade seja compreendida não apenas como possível, mas como a única forma de alcançar essa finalidade - tendo em vista que ali as internas experimentam uma maternidade tutelada pelo Estado, vivida com dedicação exclusiva e mediante a disciplina que visa ao aprendizado. Assim sendo, as regras impostas pelo Centro se tornam centrais para que as mulheres aprendam a exercer de forma satisfatória a sua maternidade, com a expectativa da devoção feminina aos cuidados dos filhos e filhas, ou seja, de acordo com a idealização social de boa mãe. Em última instância, as normas do CRGPL existem para que as mulheres mães presas aprendam a ser mães.

Em contrapartida, os discursos das profissionais da PIEP demonstram uma descrença na possibilidade de ressocializar as mulheres presas por meio do exercício da maternidade, por ser exercida de formas diversas fora do cárcere - e de certa maneira, tidas como menos legítimas pelas funcionárias entrevistadas -, e muito inviabilizada entre os muros da prisão. Nesse contexto, é justamente a rotulação de não serem boas mães que reitera o argumento apresentado aqui.

A sexualidade, por sua vez, também se configura como importante aprendizado dentro das unidades prisionais, seja por meio da sua negação ou da sua concessão momentânea. Por um lado, às mulheres grávidas e recémmães é negada a prática sexual e a sexualidade. Na PIEP, onde a sexualidade não se justifica como menos importante que a maternidade, como no Centro, os discursos das entrevistadas ainda consideram as mulheres emocionalmente mais frágeis e dependentes de afeto - e, por isso, a carência é dada como 
inerente ao cárcere feminino, justificando a busca por relacionamentos homoafetivos. Se fora dos muros da prisão as mulheres que possuem uma companheira são alvos de discriminação, no cárcere isso também é perceptível, mas o caráter provisório dessas relações as torna mais aceitáveis - desde que dentro de certos limites.

Temos, portanto, que no Centro busca-se dissociar a maternidade do exercício da sexualidade, demonstrando que mulheres mães não podem - ou não precisam - sentir prazer sexual, enquanto que na PIEP o exercício sexual é possível e concedido. Mas a ausência de visitas do companheiro regular e mesmo da comprovação de união estável tornam-se empecilhos para a concretização formal desse direito, e é nesse contexto que há uma maior concessão das relações homoafetivas dentro da prisão.

Por fim, diante das expectativas tradicionais do papel de gênero compartilhadas, é esperado também que as mulheres presas cumpram as funções domésticas, exerçam os trabalhos tidos como "femininos", valorizem o cuidado com a aparência, tenham agência apenas no ambiente privado junto a suas famílias, e sejam fiéis aos seus companheiros - a ponto, inclusive, de se envolverem no crime por causa da influência de alguns homens em suas vidas. Esses discursos, mesmo que acionados com intensidades diferentes, encontram ressonância nas duas unidades em que foi realizada a pesquisa.

Para além do que foi colocado anteriormente sobre cada um dos temas levantados, cabe dizer que, em grande medida, as prisões femininas continuam reforçando o estereótipo de gênero e reproduzindo o objetivo das primeiras instituições prisionais direcionadas às mulheres no Brasil. É nesse sentido que ser mulher no cárcere envolve tanto aspectos punitivos como processos de socialização e, em certa medida, é justamente o reforço dessas expectativas de papéis tradicionais de gênero os mecanismos da punição.

\section{Referências}

ANGOTII, Bruna.

(2011). Entre as leis da Ciência, do Estado e de Deus: o surgimento dos presídios femininos no Brasil. Dissertação de mestrado apresentada à Universidade de São Paulo.

BADINTER, Elisabeth.

(1985). Um amor conquistado. 0 mito do amor materno. Rio de Janeiro: Nova Fronteira.
BARCINSKI, Mariana.

(2009). Gender centrality in the process of identity construction of women involved in drug trafficking. Ciência \& Saúde Coletiva, v. 14, n. 5, p. 1843-1853. 
BARCINSKI, Mariana.

(2012). Expressões da homossexualidade feminina no encarceramento: o significado de se "transformar em homem" na prisão. PsicoUSF, v. 17, n. 3, p. 437-446.

BEAUVOIR, Simone.

(1949). O segundo sexo - 1. Fatos e mitos. Tradução de Sérgio Milliet. Rio de Janeiro: Nova Fronteira.

BECKER, Anna et al.

(2016). 0 cárcere e o abandono: prisão, penalização e relações de gênero. Revista Psicologia, Diversidade e Saúde, v. 5, n. 2, p. 141-154.

BERGER, Peter; BERGER, Brigitte.

(2008). Socialização: como ser membro da sociedade. In: Marialice Foracchi \& José Martins (Org.). Sociologia e Sociedade: leituras de introdução à sociologia. São Paulo: LTC, p. 200-2014.

BIROLI, Flávia.

(2018). Gênero e desigualdades: os limites da democracia no Brasil. São Paulo: Boitempo.

BRAGA, Ana Gabriela Mendes; ANGOTTI, Bruna. (2015). Da hipermaternidade à hipomaternidade no cárcere feminino brasileiro. SUR 22, v.12, n.22, p. 229-239.

CUNHA, Manuela Ivone P.

(1991). A prisão feminina como "ilha de Lesbos" e "escola do crime": discursos, representações, práticas. In: Carlos Laranjo Medeiros (Org.). Do desvio à instituição total: subcultura, estigma, trajectos. Lisboa, Centro de Estudos Judiciários, p.163-184.

CUNHA, Manuela Ivone.

(2014). Etnografias da prisão: novas direções. Configurações, n. 13, p. 47-68.

DIUANA, Vilma; CORRÊA, Marilena; VENTURA, Miriam.

(207). Mulheres nas prisões brasileiras: tensões entre a ordem disciplinar punitiva e as prescrições da maternidade. Physis, v. 27, n. 3, p. 727-747.
FIORAVANTE, Karina; SILVA, Joseli.

(2011). Do cárcere: uma discussão sobre a espacialidade cotidiana de mulheres encarceradas na cidade de Ponta Grossa, Paraná. In: Anais do XIV Encontros Nacionais da ANPUR, v. 14, p. 1-21.

GRANJA, Rafaela, CUNHA, Manuela; MACHADO, Helena.

(2012). Children on the outside: The experience of mothering among female inmates. In: Anais 3rd Global Conference Experiencing Prison, Praga, República Checa, p. 1-12.

HIRATA, Helena; KERGOAT, Danièle.

(2007). Novas configurações da divisão sexual do trabalho. Cadernos de Pesquisa, v. 37, n. 132, p. 595-609.

INFOPEN.

(2018). Levantamento Nacional de Informações Penitenciárias - Infopen Mulheres, 2. ed. Brasília.

MARTINO, Natalia.

(2019). Mulheres encarceradas: cruzamentos entre redes familiares e prisionais. Dissertação de mestrado apresentada ao Programa de PósGraduação em Sociologia da Faculdade de Filosofia e Ciências Humanas da Universidade Federal de Minas Gerais.

PARSONS, Talcot; BALES, Robert. F.

(1956). Family, socialization and interaction process. Glencoe, IL, Free Press.

PIMENTEL, Elaine.

(2008). Amor bandido: as teias afetivas que envolvem a mulher no tráfico de drogas. In: Mundos sociais: saberes e prácticas. Lisboa, Associação Portuguesa de Sociologia, p. 1-14.

PIZOLOTTO, Leticia.

(2014). A lei 11.343/2006 e o aumento de mulheres encarceradas. Trabalho de Conclusão do Curso de Graduação em Direito apresentado à Universidade Regional do Noroeste do Estado do Rio Grande do Sul.

RESENDE, Deborah Kopke.

(2017). Maternidade: uma construção histórica e social. Pretextos, v. 2, n. 4, p. 175- 191. 
SCAVONE, Lucila.

(2001). Maternidade: transformações na família e nas relações de gênero. Interface, v.5, n.8, p.47-59.

SCOT, Joan.

(1989). Gênero: uma categoria útil para análise histórica. Trad. Christiane Rufino

Debat e Maria Betânea Ávila. New York City, Columbia University Press.

SOARES, Bárbara Musumeci; ILGENFRITZ, Iara.

(2002). Prisioneiras: vida e violência atrás das grades. Rio de Janeiro: Editora Garamond.
VÁSQUEZ, Georgiane.

(2014). Maternidade e Feminismo: notas sobre uma relação plural. Revista Trilhas da História, v.3, n. 6, p.167-181.

\section{Recebido em}

setembro de 2020

\section{Aprovado em}

maio de 2021 